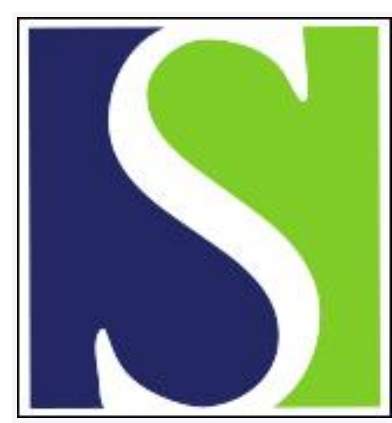

Scand J Work Environ Health 1996;22(3):227-229

https://doi.org/10.5271/sjweh.136

Issue date: Jun 1996

Is skull sawing by autopsy assistants overlooked as a cause of vibration-induced white fingers?

by Torén $\mathrm{K}$, Jonsson $\mathrm{P}$

Key terms: autopsy; raynaud's phenomenon

This article in PubMed: www.ncbi.nlm.nih.gov/pubmed/8837270

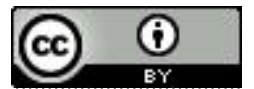




\title{
Is skull sawing by autopsy assistants overlooked as a cause of vibration-induced white fingers?
}

\author{
by Kjell Torén, MD,' Per Jonsson, MSc ${ }^{1}$
}

\author{
Torén $\mathrm{K}$, Jonsson $\mathrm{P}$. Is skull sawing by autopsy assistants overlooked as a cause of vibration-induced white \\ fingers? Scand J Work Environ Health 1996;22:227-9.
}

\begin{abstract}
Background Workers using vibrating tools have an increased prevalence of vibration-induced white fingers. One example of such workers is autopsy assistants, who use vibration for skull sawing.

Case history A previously healthy 42 -year-old Swedish male smoker had worked as an autopsy assistant at a forensic department between 1977 and 1991. He prepared corpses for autopsy, including sawing the skulls with an electric saw. Beginning in 1983, his right index finger blanched in cold. During subsequent years the blanching spread to the other fingers on the right hand, except for the thumb. The findings in the physical examination and the results of blood tests were normal. Digital blood pressure after cooling showed a severe vasospastic reaction in both middle fingers. Vibration measurements during skull sawing showed a frequencyweighted acceleration level of $8.9 \mathrm{~m} \cdot \mathrm{s}^{-2}$.

Questionnaire survey A questionnaire was mailed to all assistants $(N=17)$ preparing autopsies and to all medical examiners, as referents $(\mathrm{N}=18)$, at the Swedish Institutes of Forensic Medicine. It was answered by 13 assistants (76\%), 1 woman and 12 men, and 16 medical examiners (89\%), 3 women and 13 men. Eleven of the assistants ( $85 \%$ ), including one woman, and one of the physicians (6\%), a man, reported a history of blanching fingers provoked by chill (difference $79 \%, P=0.00003$, Fisher's exact test).

Conclusions Autopsy assistants at forensic departments seem to have an increased prevalence of self-reported blanching fingers, which may be an effect of exposure to high levels of vibration.
\end{abstract}

Key terms autopsy, Raynaud's phenomenon.

Workers using vibrating tools have an increased prevalence of vibration-induced white fingers (1). When sawing skulls in autopsies, the assistants use a vibrating electric saw. This report describes an autopsy assistant with vibration-induced white fingers and a small crosssectional survey indicating that autopsy assistants have a high prevalence of blanching fingers.

\section{Case history}

The index case was a 42-year-old man who had smoked 20 cigarettes daily since 20 years of age. He had no previous history of circulatory or systemic diseases, and he did not use medicines regularly. Between 1977 and 1990 he worked as an autopsy assistant at the forensic department in a university hospital. Since 1991 he has had a job without exposure to vibration.

At the forensic department, he prepared corpses for autopsy, including sawing of the skulls. He estimated that he sawed five to seven skulls daily, duration about $1 \mathrm{~h}$. The saw was electrical, mainly held by his right hand.

Beginning in 1983, his right index finger blanched in cold. During subsequent years the blanching spread to the other fingers of the right hand, except for the thumb. The findings in the physical examination were normal. The results of blood tests, including erythrocyte sedimentation rate (Westergren), hemoglobin concentration, and immunoglobulin (Ig) concentrations (IgG, IgA, $\operatorname{IgM}$ ), were normal. Antinuclear antibodies were negative but rheumatic factor (Waaler-Rose) was present (1/40). Digital blood pressure was measured in the middle fingers after cooling (2). In the right finger the systolic blood pressure was reduced to $32 \%$ at $13^{\circ} \mathrm{C}$ and on the left side to $36 \%$ at $14^{\circ} \mathrm{C}$. Vibration measurements were performed during skull sawing using the same type of saw the patient had used at work (Aesculap Oscillant den.

Reprint requests to: Dr Kjell Torén, Institute of Internal Medicine, Section of Occupational Medicine, Sahlgrenska University Hospital, St Sigfridsgatan 85b, S-412 66 Göteborg, Sweden. 
PGP 024). The vibration was registered on a tape recorder (Bruel\&Kjaer 7007) with three perpendicular accelerometers (Bruel\&Kjaer 4393) glued onto the saw. Frequency analyses were made in the laboratory, with a real-time analyzer (RION SA 24), and the frequencyweighted vibration level was calculated $(3,4)$. The frequency-weighted acceleration in the dominant direction during skull sawing was $8.9 \mathrm{~m} \cdot \mathrm{s}^{-2}$. With the saw unloaded the acceleration level was $3.5 \mathrm{~m} \cdot \mathrm{s}^{-2}$.

\section{Cross-sectional survey}

A short questionnaire about the history of blanching fingers, work tasks, and occupational history was sent to all assistants $(\mathrm{N}=17)$ who prepared copies for autopsies at the Swedish Institutes of Forensic Medicine (index case not included). It was answered by 13 assistants (76\%), 1 woman and 12 men. The medical examiners $(N=18)$ at the same institutes served as unexposed referents. Sixteen of them ( $89 \%$ ) answered the questionnaire, 3 women and 13 men. The question about blanching fingers was worded "Do you suffer from white fingers? We define white fingers as one or more fingers that blanch and grow numb in cold weather."

The mean age of the assistants was 47.8 range (33$60)$ years, and their mean time of employment as assistants was 17 (range 5-28) years. Before 1991, the mean number of skulls sawed daily was 5.6 (range $4-8$ ), and thereafter the mean number dropped to 3.3 (range 1-6). Two of the assistants had been exposed to vibration before their current employment. The mean age of the medical examiners was 44.9 (range $37-61$ ) years.

Eleven of the assistants (85\%), including the woman, and one male medical examiner $(6 \%)$, reported white fingers in cold weather. The difference, $79 \%$, was statistically significant ( $P=0.00003$, Fisher's exact test). The physician mentioned that he had suffered from blanching fingers since his teens.

\section{Discussion}

The patient presented in this report suffered from vibration-induced white fingers. The diagnosis is supported by his clinical history of progressive Raynaud's phenomenon, a positive cold provocation test, and the fact that the symptoms had occurred after six years of exposure to vibration. However, the cold provocation test showed a cold-induced vasospasm in bilateral fingers, which may point against an exposure-induced disease, as he mainly used his right hand to hold the saw.

The vibration measurements during skull sawing showed a high vibration level during sawing but a considerably lower level when the saw was unloaded. The measurements were conducted by an occupational hygienist with experience with vibration measurements.
The subsequent cross-sectional pilot survey of autopsy assistants at institutes of forensic medicine indicated that this occupational group may have an increased prevalence of Raynaud's phenomenon.

The diagnosis of Raynaud's phenomenon in this pilot study was however based on answers to a self-administered questionnaire, and some degree of misclassification is of course present. The validity of the question about white fingers was assessed in a random population sample of 2044 subjects aged 20 to 50 years (Barregård \& Torén, unpublished data). A physician carried out a telephone interview of the positive responders and of a sample of the negative responders, the specificity being 0.98 and the sensitivity being 0.75 . In a study about primary Raynaud's phenomenon among women, a similar question worded "Are you troubled by cold and white fingers, either with or without numbness?" was validated (5). From the figures in that paper a specificity of 0.95 and a sensitivity of 0.89 could be calculated.

There is also a misclassification in relation to primary Raynaud' phenomenon, but it is probably of less importance, as the exposed subjects were mainly men.

The smoking and snuff habits probably differed between the groups, but it is unclear whether tobacco use increases the risk of Raynaud's phenomenon or vibration-induced white fingers. It may, however, elicit vasoconstriction (1). Hence, the results may be confounded by nicotine consumption to some extent.

For legal reasons, technicians at forensic departments have to saw skulls more frequently than technicians preparing routine autopsies. However, a new law regulating autopsies in Sweden has resulted in a decrease in the number of skulls sawed, and therefore exposure to vibration has probably decreased among autopsy technicians.

In conclusion, despite the small size and presence of uncontrolled confounding, the present report suggests that autopsy assistants at forensic departments may have an increased prevalence of self-reported blanching fingers (ie Raynaud's phenomenon) probably as an effect of vibration exposure during skull sawing.

\section{Acknowledgments}

This study was supported by the Swedish Council for Work-Life Research.

\section{References}

1. Gemne G, Lundström R, Hansson J-E. Disorders induced by work with hand-held vibrating tools. Stockholm: Arbetarskyddsverket, 1993. Arbete och hälsa 6.

2. Nielsen L, Lassen NA. Measurement of digital blood pressure after local cooling. J Appl Physiol 1977;43:907-10.

3. International Organization for Standardization (ISO). Guidelines for the measurement and the assessment of human exposure to hand-transmitted vibration. Geneva: ISO, 1985. ISO/ 
DIS 5349:2.

4. Torén K, Jonsson P, Nilsson R. Vasospastic disease among laboratory technicians using test tube mixers: a report of two cases. Am J Ind Med 1992;21:601 -4.

5. Leppert J, Åberg H, Ringqvist I, Sörensson S. Raynaud's phe- nomenon in a female population: prevalence and association with other conditions. Angiology 1987;38:871-7.

Received for publication: 19 December 1995 